\title{
Importance of Preoperative Magnetic Resonance Imaging Evaluation of the Anterior Cruciate Ligament Injuries
}

\author{
Barıș Polat' (D, Mehmet Alp Dirik² (1), Ayșe Esin Polat ${ }^{3}$ (1) \\ 'Department of Orthopaedics and Traumatology, Near East University, Nicosia, Cyprus \\ ${ }^{2}$ Department of Radiology, Dr. Suat Günsel Kyrenia University, Kyrenia, Cyprus \\ ${ }^{3}$ Department of Orthopaedics and Traumatology, Dr. Akçiçek State Hospital, Kyrenia, Cyprus \\ ORCID IDs of the authors: B.P. 0000-000I-8229-64I2; M.A.D. 0000-000I-9427-282I; A.E.P. 0000-000I-9592-5193.
}

Cite this article as: Polat B, Dirik MA, Polat AE. Importance of Preoperative Magnetic Resonance Imaging Evaluation of the Anterior Cruciate Ligament Injuries. Cyprus J Med Sci 2018; 3(3): 178-85.

\begin{abstract}
Patients with a clinically suspected tear of the anterior cruciate ligament $(A C L)$ are generally diagnosed using magnetic resonance imaging (MRI). It is accepted that MR is the most effective radiological modality for diagnosing ACL injuries. Formerly, the essential aim of MRI was to detect whether the ACL tear was partial or total. Recently, however, there has been an increasing interest in the region of rupture. In addition, it is highly important to focus on the tissue quality of the remaining ligament. These findings will help the orthopedic surgeon to choose the right surgical treatment technique. In this review, the classical MRI findings of the ACL injuries, as well as the location of the injured region and the quality of the remaining tissue, are addressed.
\end{abstract}

Keywords: Knee, magnetic resonance imaging, anterior cruciate ligament

\section{INTRODUCTION}

Every year, there is a statistically growing number of knee ligament injuries due to an increase in sports activities. The anterior cruciate ligament $(A C L)$ tear or sprain is considered to be one of the most common sports injuries. The incidence of $A C L$ rupture is 35 per 100,000 (I). An ACL injury may lead to pain, recurrent instability, progressive meniscus injury and cartilage damage, decrease in the quality of life, and finally osteoarthritis of the knees (2). The first surgical interventions for the ACL rupture were performed in the 1970s as open repair $(3,4)$. This treatment was abandoned after it was realized that the mid-term outcome was not satisfying. Arthroscopic ACL reconstruction is nowadays a standard treatment option following $\mathrm{ACL}$ rupture in active patients. The success rate of the arthroscopic $\mathrm{ACL}$ reconstruction has been reported as ranging between $70 \%$ and $90 \%(5,6)$. In this standard treatment, the location of the tear and the quality of the remnant tissue was not important, so ruptured $A C L$ debridement was the standard surgical procedure.

The $A C L$ is composed of two functional bundles. These bundles are the anteromedial bundle (AM) and posterolateral bundle (PL), according to their insertion to tibia (7). An isolated PL or AM bundle reconstruction can be performed in the presence of clinical and magnetic resonance imaging (MRI) findings due to the inability of one bundle to function and the other to be inadequate $(8,9)$. With a selective bundle reconstruction in partial $A C L$ tear, at least a full $A C L$ reconstruction or even better results can be obtained. In addition, the advantages of preserving the proprioceptive functions of the ligament and having surgery with less morbidity are endured.

Despite anatomical and selective reconstruction techniques, the quest for ideal treatment in ACL surgery continues. Preservation of the injured $A C L$ tissue can provide the maintenance of the proprioceptive and natural knee kinematics and is thought to accelerate healing by reducing surgical morbidity. More recently, arthroscopic primary repair of ACL tears is becoming popular again. DiFelice et al. (10) reported very successful results of the arthroscopic primary repair in patients with proximal tears, which are called type I, and good remnant tissue quality. Some authors agree with these findings (II, 12). This review emphasizes that the proximal ACL tear and good remnant tissue quality are critical for a successful outcome of the arthroscopic primary ACL repair. 
The assessment of soft tissue injuries in the knee joint with MRI has also established itself as the next diagnostic tool, following physical examination and x-ray. It is accepted that MRI is the most effective radiological method with $90 \%$ to $95 \%$ sensitivity and $95 \%$ to $100 \%$ specificity when assessing ACL injuries. In addition, if the MR images are not optimized, the technique can be less reliable in partial or chronic ruptures $(13,14)$. When direct and indirect findings in MRI of knee are evaluated together, much information can be obtained about the affected bundle, rupture site, and the residual tissue quality of the $A C L$ tear.
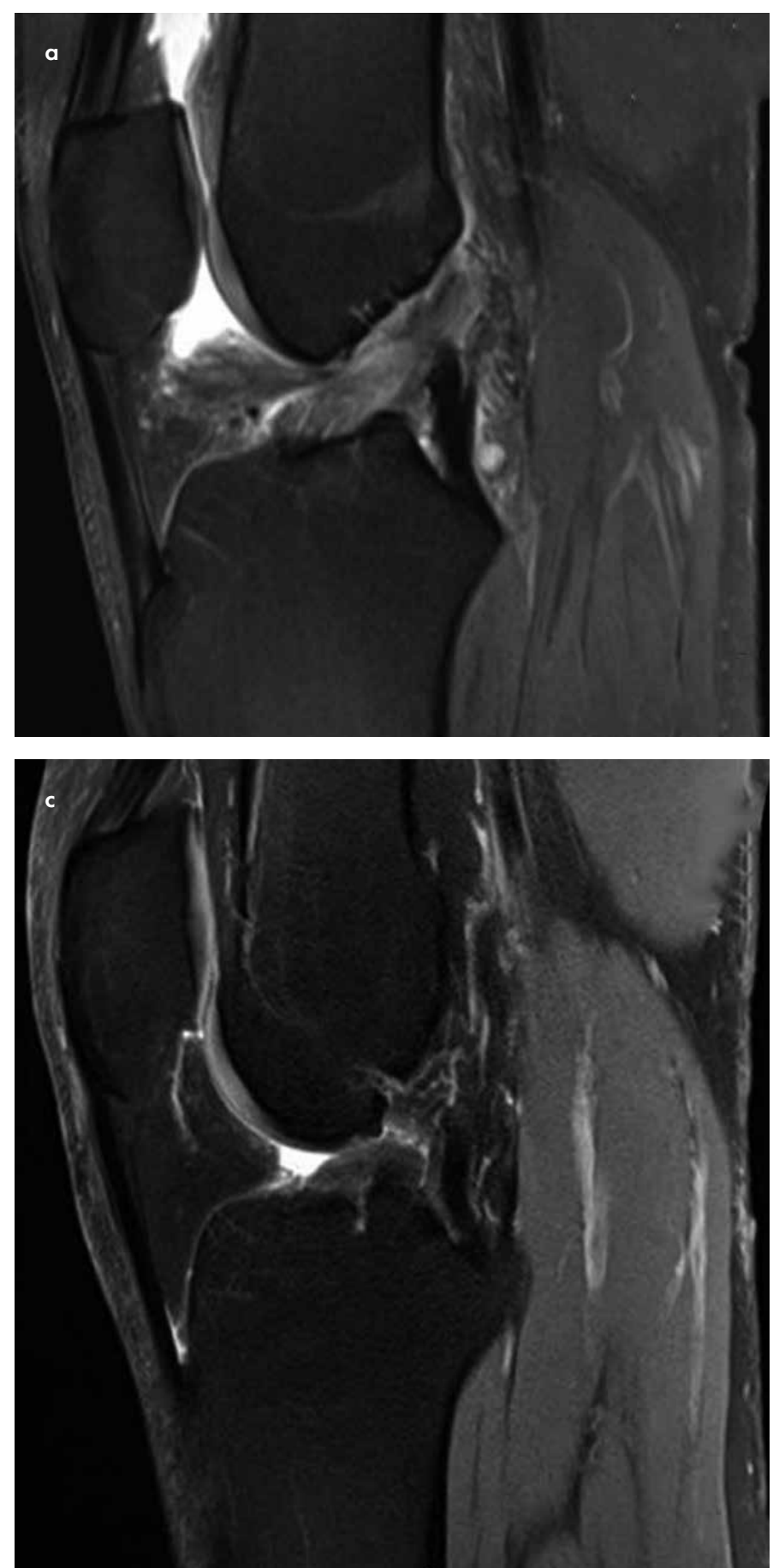

The aim of this review is to emphasize the importance of the affected bundle, the location of the injury and the structure of the remnant $A C L$ tissue, as well as to discuss the classical findings of MRI with the ACL injury. These findings may guide the orthopedic surgeon to choose the right surgical treatment technique.

\section{Knee MRI}

All examinations were performed with a 3.0T MRI machine (Siemens, Magnetom, Skyra, Erlangen, Germany) and a l6-channel knee-dedicated tx $r x$ in our clinic. We used our standardized protocol, which has three sequences in the sag-
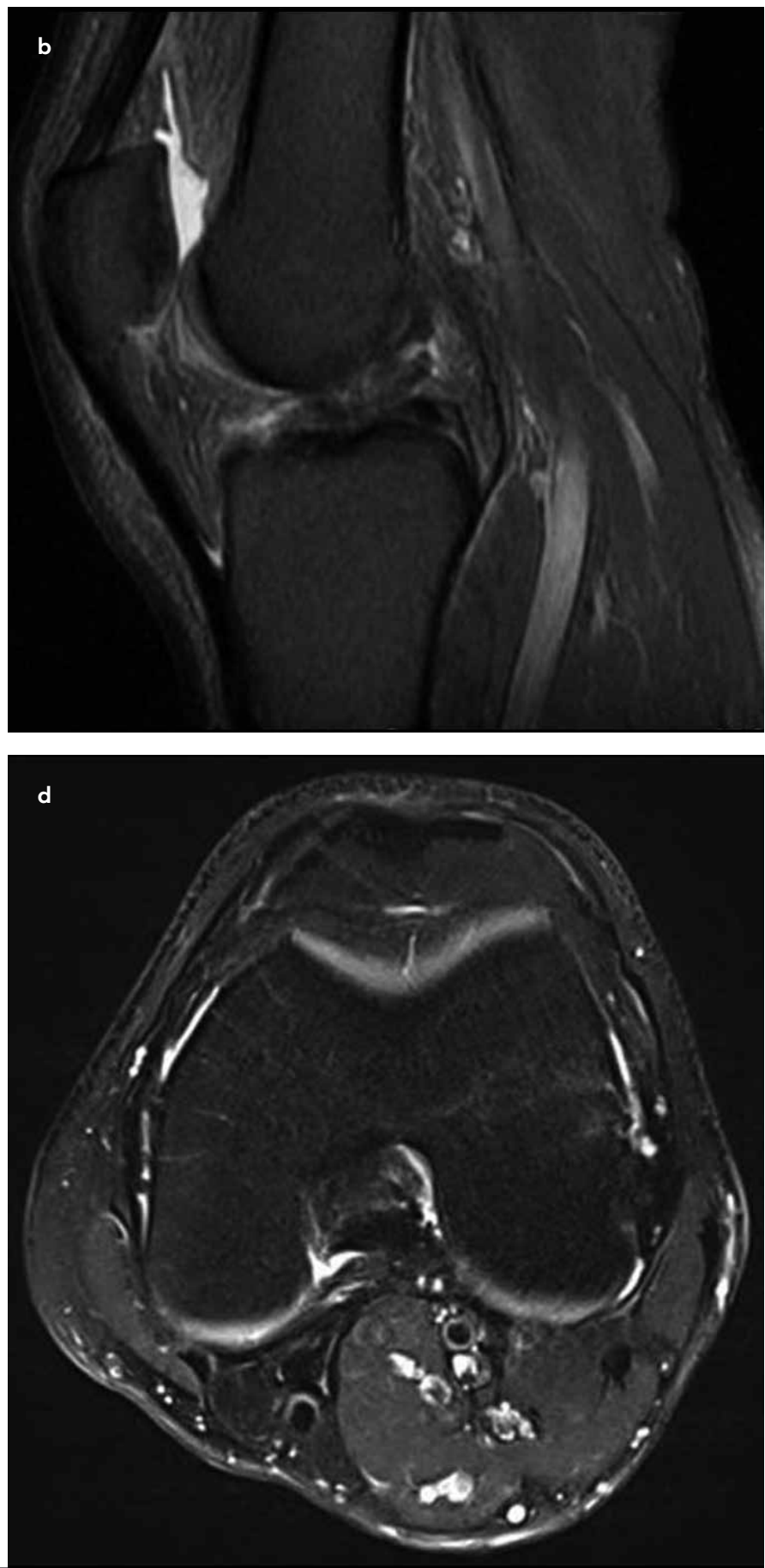

FIGURE I. a-d. Three separate sagittal proton-density MRI images of the knees depict the anterior cruciate ligament disruption. Acute injury (a) subacute injury (b) chronic injury (c). Axial proton-density MRI images of the knee depicting a chronic anterior cruciate ligament disruption and "empty notch sign" (d). 


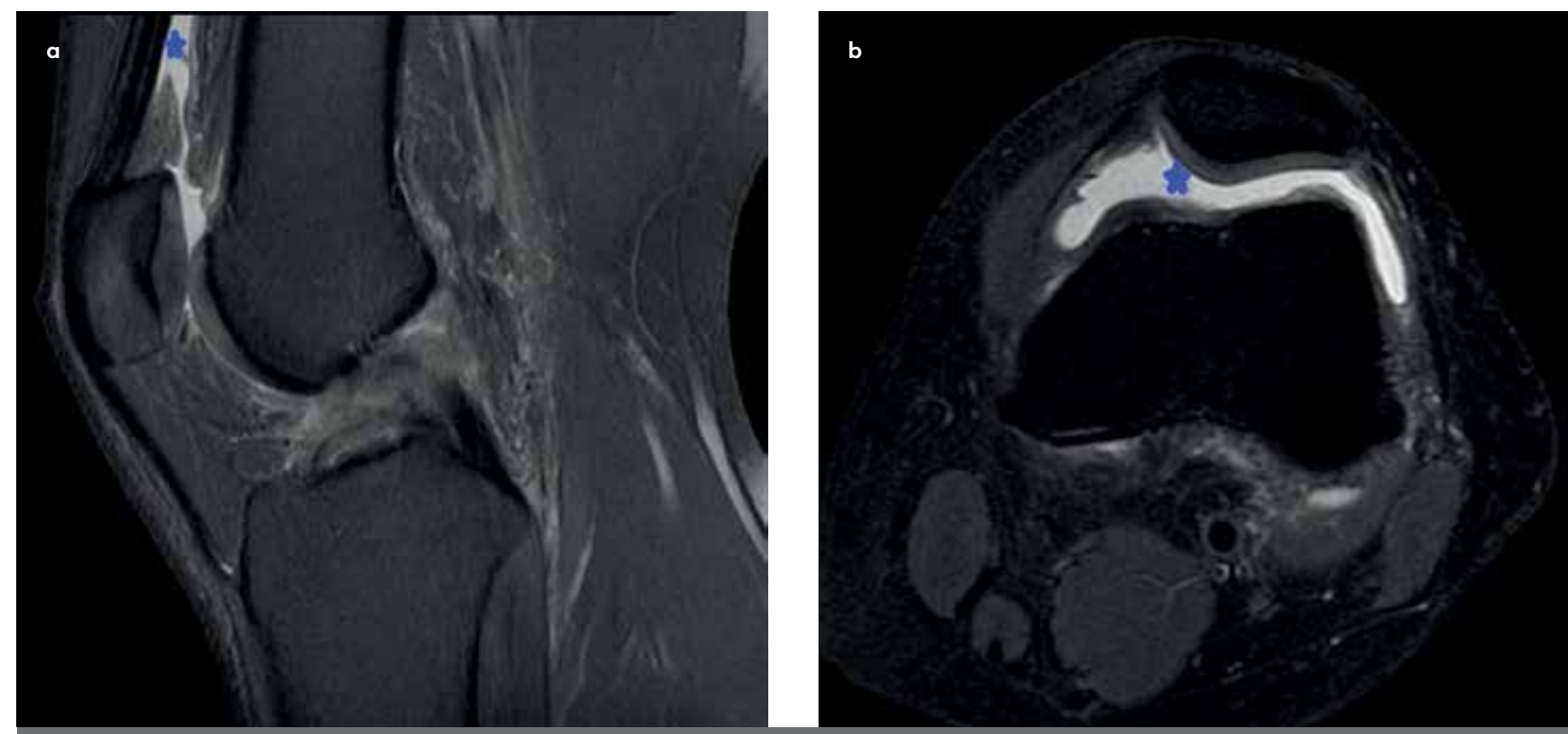

FIGURE 2. a-b. Sagittal proton-density MRI image of the knee: The asterisk marks the hemarthrosis. (a) Axial proton-density MRI image of the knee: The asterisk marks the hemarthrosis (b).

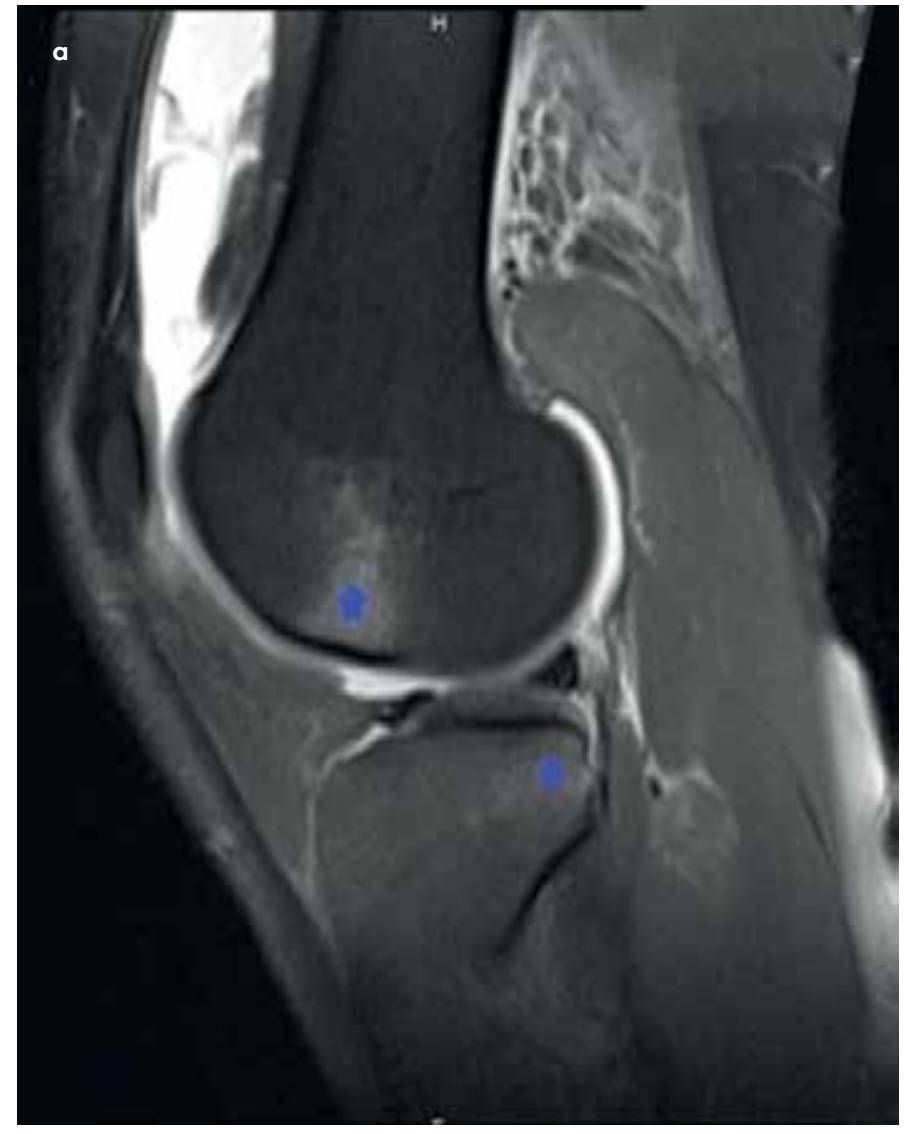

$\mathbf{R}_{\mathrm{b}}$

FIGURE 3. a, b. Sagittal T2 proton-density of knee: The asterisk marks the central third of the lateral femoral condyle and posterior third of the lateral tibial plateau bone bruise (a) Lateral knee direct graphy: The arrow marks deep sulcus (terminalis) sign (b). 
ittal orientation [I- fat-suppressed proton-density weighted turbo spin-echo (FS PD TSE) sequence 2; TI-weighted turbo spin-echo sequence 3; T2 with water excitation (T2 DE3D WE) sequence]; two sequences in the coronal orientation [Ifat-suppressed proton-density weighted turbo spin-echo (FS PD TSE) sequence 2; T2 turbo inversion recovery magnitude short tau inversion recovery (T2_TIRM_COR(STIR) sequence], and one sequence in the axial orientation [I-fat-suppressed proton-density weighted turbo spin-echo (PD_TSE_FS_TRA) sequence]. The parameters used for image acquisition were a $320 \times 256$ matrix and $3.0 \mathrm{~mm}$ slice thickness with $0.3 \mathrm{~mm}$ interslice gap.

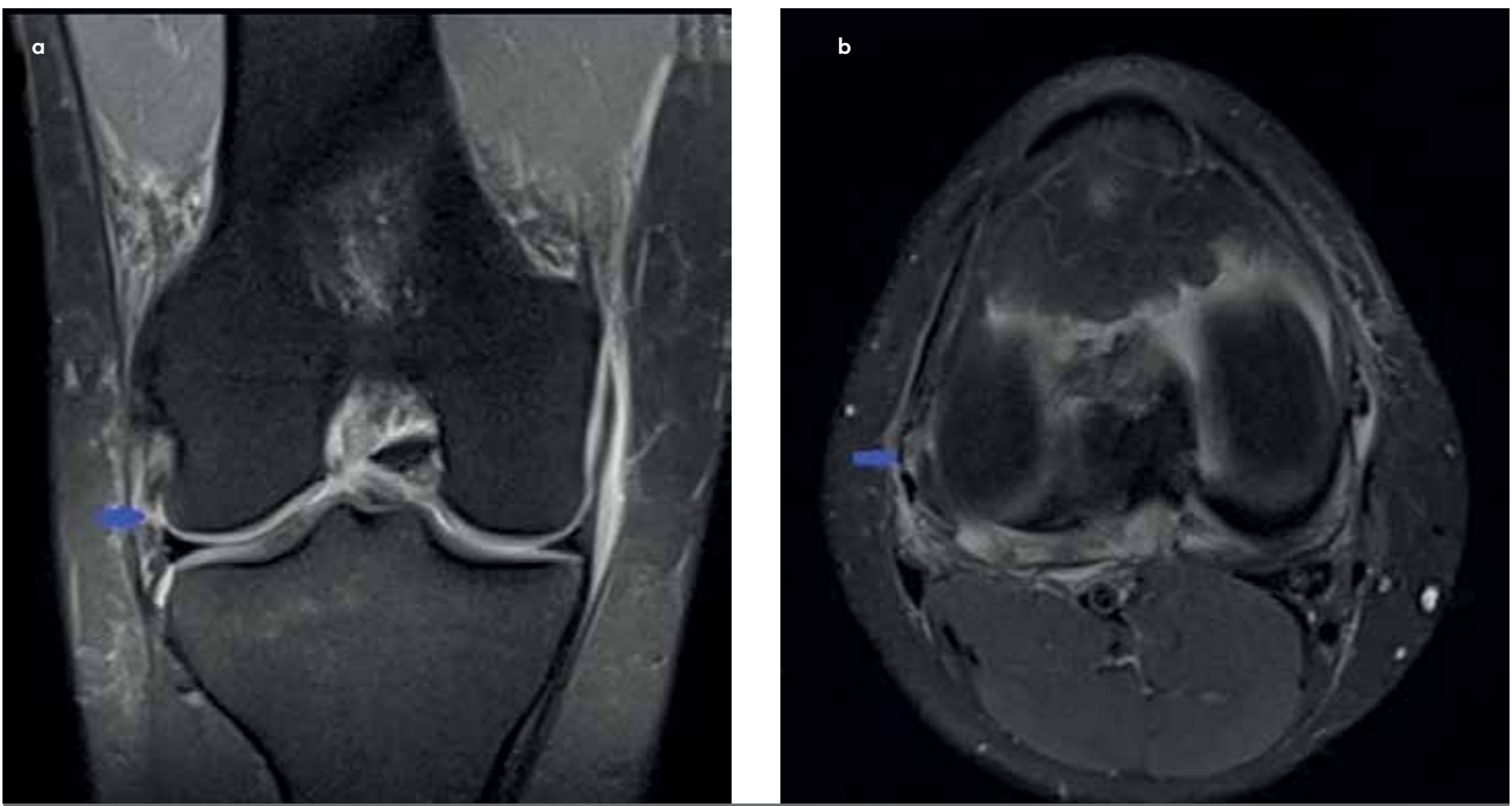

FIGURE 4. a, b. Coronal proton-density MRI image of the knee: The arrow marks disruption of the femoral part of the anterolateral ligament (a) Axial proton-density MRI image of knee: The arrow marks anterolateral ligament (b).

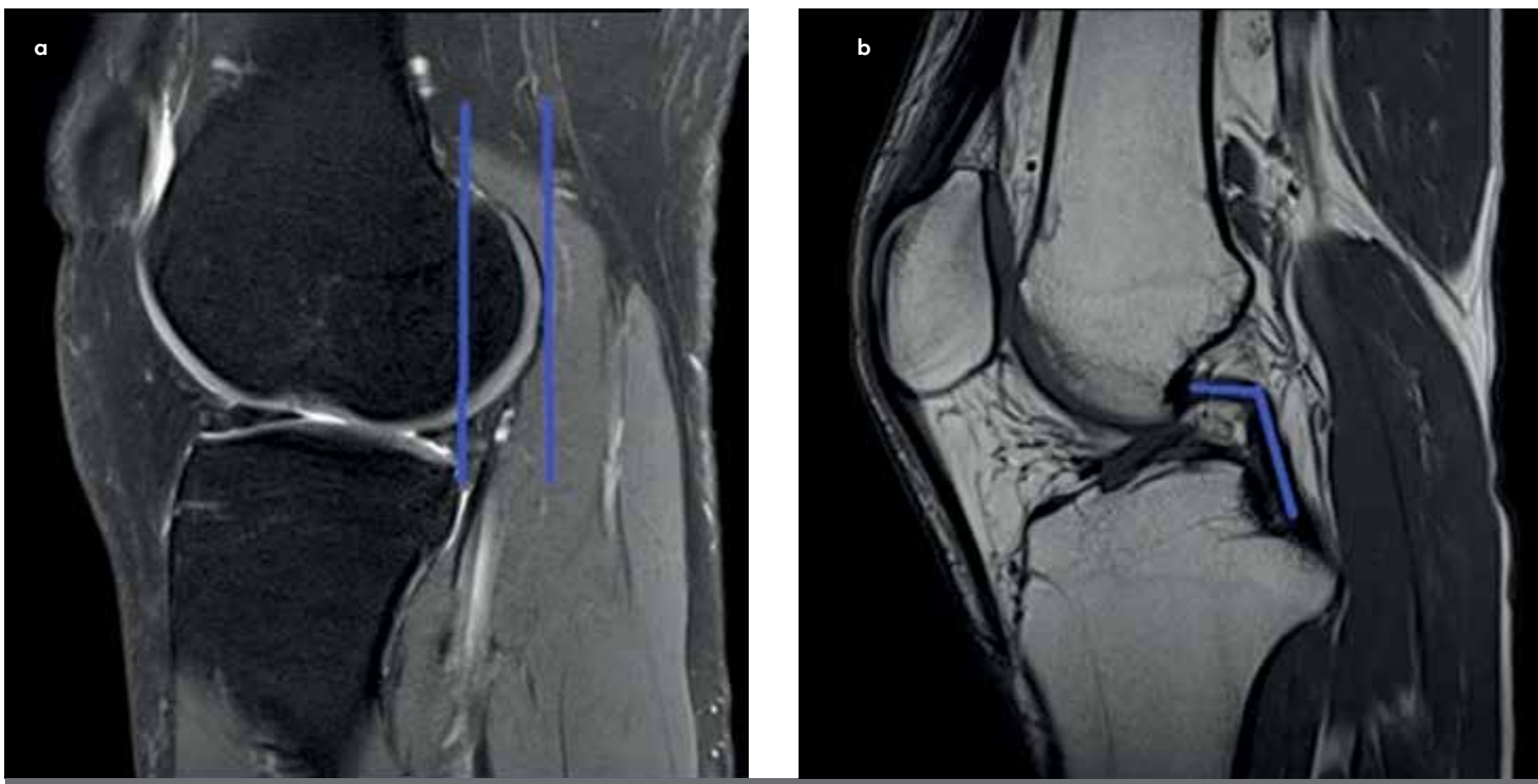

FIGURE 5. a, b. Sagittal proton-density MRI image of the knee: The amount between two longitudinal lines shows the anterior tibial translocation. (a) Sagittal TI MRI image of the knee: The angle between the two blue lines shows the PCL buckling (b). 

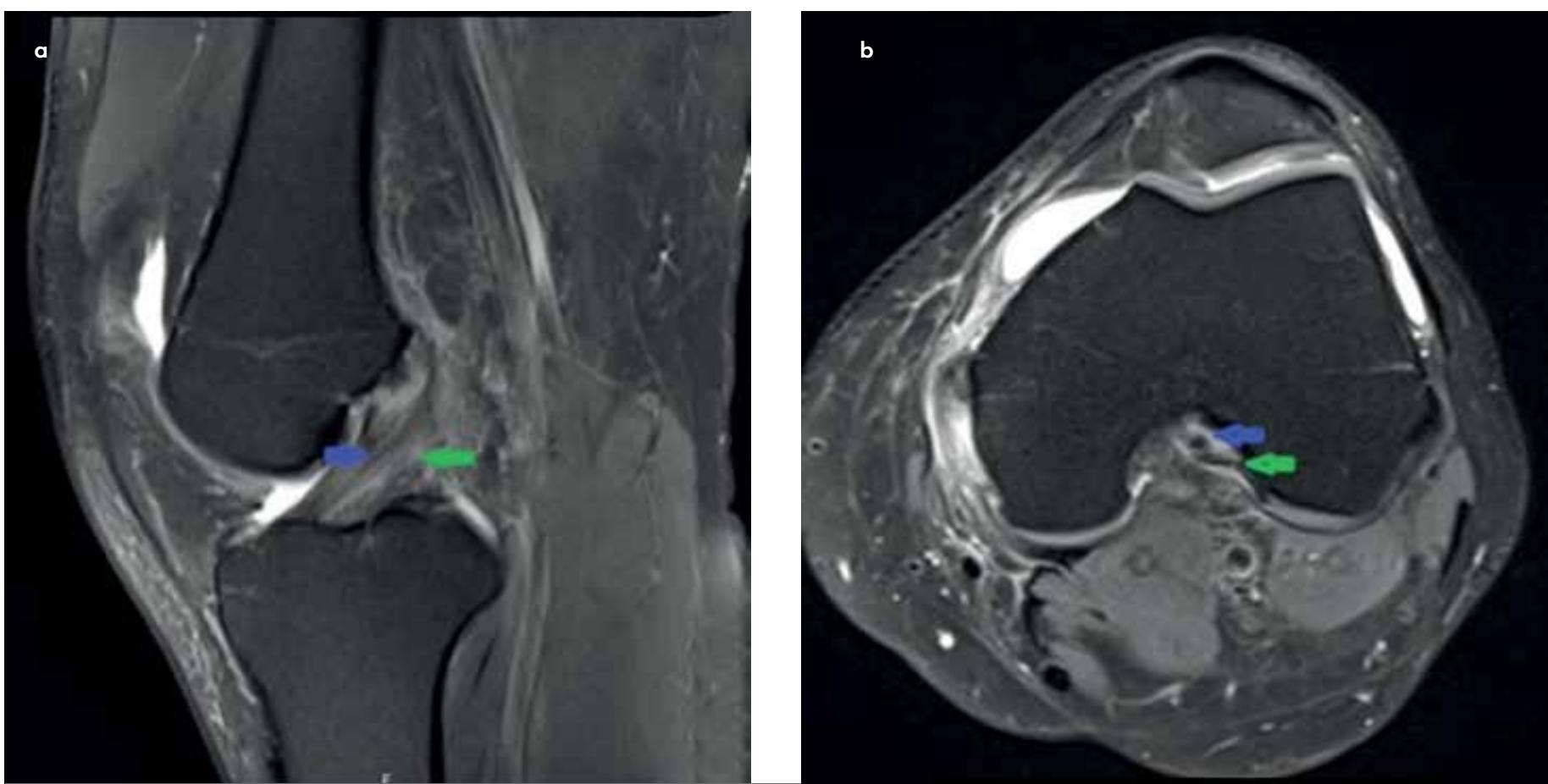

FIGURE 6. a, b. Sagittal proton-density MRI image of the knee: The blue arrow shows intact anteromedial bundle; the green arrow shows disrupted posteromedial bundle. (a) Axial proton-density MRI image of the knee: The blue arrow shows disrupted posterolateral bundle femoral attachment; the green arrow shows intact anteromedial bundle femoral attachment (b).

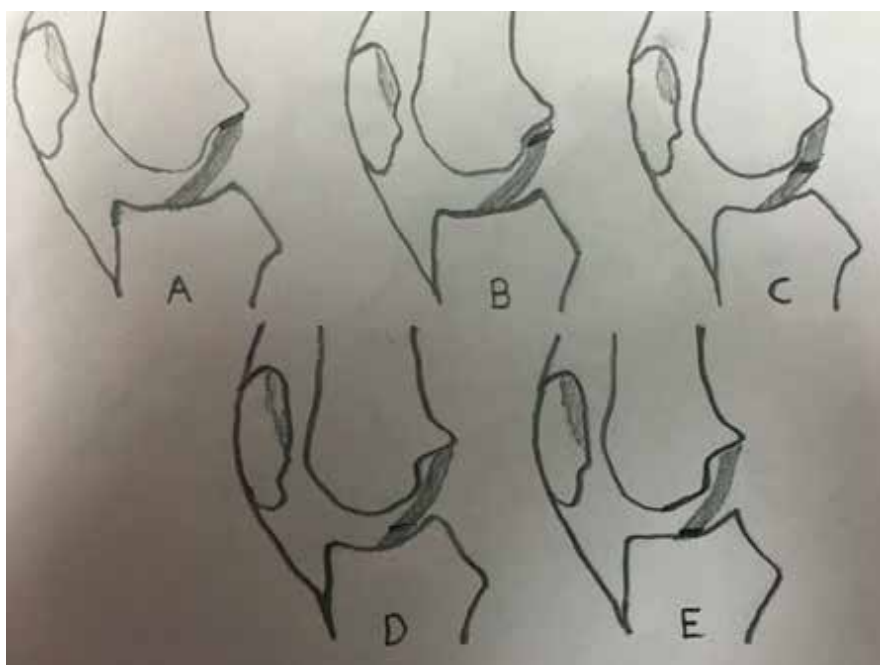

FIGURE 7. a-e. Tear type classification (Drawings by B. Polat). Type I proximal avulsion tear (a). Type II proximal tear (b). Type III midsubstance tear (c). Type IV distal tear (d). Type $V$ distal avulsion tear (e).

A normal $A C L$ is characterized by continuous, homogeneous low-signal intensity fibers, extending from the intercondylar notch of the tibial plateau to the medial aspect of the lateral femoral condyle. The ACL is best visualized with a turbo spin echo (TSE) sagittal intermediate weighted sequence and axial intermediate weighted with fat-suppression sequence. In addition, tibial attachments of the AM and PL bundles can be seen with coronal images.

Knee MRI scans were evaluated for the presence or absence of the following direct and indirect signs. These signs are discussed below.

\section{DIRECT SIGNS}

The direct signs of acute ACL tears consist of a structural integrity at any plane (axial, coronal, or sagittal) in the morphology of $A C L$, abnormal ligament contour, and abnormal MRI signal characteristics of the ligament itself. MRI studies performed in the acute period may show hyperintense appearance in the sagittal T2 sequences and are indicative of the loss of integrity and edema (Figure la). In the subacute period, the edematous appearance gives place to the fragmented appearance of lower intensity (Figure lb). In the chronic period, the ACL may appear to be completely absent or undulated in the T2-weighted sagittal and axial sequence (Figure Ic, d) which can be named "empty notch sign" (I5).

\section{INDIRECT SIGNS}

\section{Hemarthrosis}

Anterior cruciate ligament injury is the most common reason of traumatic knee hemarthrosis. The reason for acute hemarthrosis is injury to the branches of the middle geniculate artery. Bomberg et al. (16) reported that acute traumatic hemarthrosis in $71 \%$ of patients is caused by an ACL tear. Other most common causes of traumatic knee hemarthrosis are patellar dislocation and meniscal tear. Hemarthrosis is not considered a specific finding indicative of $A C L$ injuries. It can be seen in the overall joint, particularly in the suprapatellar pouch, presenting as hyperintense in $\mathrm{TI}$ and intermediate to hyperintense in T2 sequence (Figure 2a, b).

\section{Bone Bruise and Deep Sulcus Sign}

When the $A C L$ is torn, anterior translation of the tibia leads to abnormal contact of the lateral femoral condyle and lateral tibial plateau. This abnormal contact leads to microtrabecular fractures, edema, and hemorrhage on the subchondral bone. This condition is called bone marrow edema or bone bruise on 
MRI. Generally, it is accepted that most common bone bruise locations in case of an acute ACL tear is the central third of the lateral femoral condyle and posterior third of the lateral tibial plateau (Figure 3a). This bone bruise pattern is sometimes seen in the medial compartment during severe injuries. Dunn et al. (17) reported that 418 of $525(80 \%)$ patients with ACL tear had bone bruise imaging findings. Osteochondral depression of lateral femoral condyle in sulcus terminalis where a junction between the weight bearing tibial articular surface and the articular patellar surface of the femoral condyle, can be called "deep sulcus terminalis sign" (18). An average of $2 \mathrm{~mm}$ of collapse on the lateral femoral sulcus can be seen on direct graphy, as well as on MRI (Figure 3b). In a MR review study, bone contusions or bruise in the lateral compartment of the knee increased the specificity and positive predictive value in the ACL injury (19).

\section{Segond Fracture or Anterolateral Ligament (ALL) Rupture}

The abnormal varus stress and internal rotation of the tibia during the $A C L$ injury causes the avulsion fracture of the lateral tibial condyle, which is called the Segond fracture. The Segond fracture is actually a bony avulsion of the ALL (20). This lesion, which is better seen on a direct graph, may also be detected on MRI.

Anterolateral ligament originates from the lateral femoral epicondyle, and it has a diagonal course and inserts at the anterolateral part of the tibial plateau, which is posterior to Gerdy's tubercle (2I). Based on previous anatomic studies, the ALL has been divided into three segments: femoral (from the origin to the bifurcation point); meniscal (from the meniscal insertion to the bifurcation point); and tibial (from the tibial insertion to the bifurcation) parts $(21,22)$. Fat-saturated $T 2$ weighted, proton-density weighted coronal and axial images of magnetic resonance generally show ALL precisely. With the coronal view, the meniscal part, the femoral part and the tibial part of the anterolateral ligament are easily observed (Figure $4 \mathrm{a}$ ). With the axial view, ALL can be seen just in front of the lateral collateral ligament (Figure 4b) (23). Helito et al. (24) found that $32.6 \%$ of patients with a torn ACL had ALL injuries.

\section{Anterior Tibial Translocation}

Magnetic resonance studies of the sagittal section of the lateral femoral condyle were described as an indirect finding if there was a $7 \mathrm{~mm}$ or greater anterior translocation of the tibia relative to the femur (25). The amount of anterior tibial translocation is measured by calculating the distance between the posterior edges of lateral femoral condyle and the posterior edges of the tibia by drawing tangential vertical lines. The measurement should be made in the middle of the lateral femoral condyle of the sagittal plane images (Figure $5 \mathrm{a}$ ). The mean anterior translocation amount in chronic ACL tears is $8.7 \mathrm{~mm}$ on average, while in acute $A C L$ tears, it is $5.4 \mathrm{~mm}$ on average. The anterior tibial translocation has been shown to increase with time (26). This finding is considered equivalent to the physical examination of the anterior drawer test. According to Vahey et al. (25), the tibial anterior translocation was a specific finding for the ACL tear. It is accepted that subluxation of at least $5 \mathrm{~mm}$ has $58 \%$ sensitivity and $93 \%$ specificity for an ACL tear.

\section{Buckling of the Posterior Cruciate Ligament}

In the sagittal imaging of knee MRI with ACL tears, the sigmoidal orientation develops in the posterior cruciate ligament
$(P C L)$ due to the anterior translation of the tibia relative to the femur (27). This sign is called buckling of the PCL, and it can be observed with acute or chronic $A C L$ tears (Figure $5 b$ ). In some studies, it has been reported that sigmoidal or curved appearance of PCL is more common in chronic $A C L$ tears than in acute $A C L$ tears (28). Yoo et al. (29) found that the reason for PCL buckling is the anterior subluxation of the tibia with $A C L$ tears, and they also noted that hyperbuckling disappears after $A C L$ reconstruction. For this reason, the PCL buckling observed after an $A C L$ reconstruction is an indication of $A C L$ laxity.

\section{Tear Location of and the Residual Tissue Quality of $\mathrm{ACL}$}

Partial $A C L$ injuries that affect the $A M$ or $P L$ bundle constitute approximately $30 \%$ of all ACL injuries (Figures 6a, b) (30). Biomechanical studies have shown that the PL bundle affects the rotational stability (pivot shift test), and the AM bundle affects the antero-posterior translational stability (anterior drawer test) (31). It is easy to diagnose complete ACL tears, compared to partial tears (sensitivity of $62 \%-81 \%$; specificity of $19 \%-97 \%$; and accuracy rates of $25 \%-53 \%$ ) (32). An oblique axial sequence, thin slice, and the use of 3 Tesla MRI may increase these accuracy rates $(33,34)$. In contrast to physical examination and MR assistance, a definitive diagnosis of partial ACL tears is determined during arthroscopy. Although a definitive decision of selective reconstruction for partial $\mathrm{ACL}$ injury is given during arthroscopy, a well-evaluated MRI will guide to the surgeon before surgery.

Current $\mathrm{ACL}$ reconstruction procedures, which are called anatomic or double-bundle reconstruction, have limitations. Approximately, the failure rate of $10 \%$ can be found in the ACL reconstruction surgery. Limitation of movement, arthrosis, and recurrent instability are the main reasons of such failure (35). Recent biomechanical studies have suggested that the ACL reconstruction is not always successful with regard to gaining normal knee kinematics and does not totally prevent early osteoarthritis in the knee $(36,37)$. Arthroscopic ACL repair has many theoretical advantages over reconstruction. These advantages have gradually increased the interest in this surgical technique in recent years. With this technique, a normal knee kinematics is more effectively preserved, and the development of osteoarthritis is prevented as the patient's ACL is preserved (38). Arthroscopic ACL repair does not require graft tissue and bone tunnels, which provides shorter surgical time and recovery with fewer complications than the $A C L$ reconstruction surgery (39). A detailed MRI evaluation is mandatory preoperatively if arthroscopic $A C L$ repair is considered. The success of the surgery is directly affected by the remnant tissue quality and the localization of the tear. The modified Sherman classification system helps to classify the tear localization in five types (Figure 7). In Type I tear, the femoral part of ACL is avulsed, but more than $90 \%$ of the distal ACL is intact. In Type 2, there is a proximal tear with $75 \%-90 \%$ of intact distal ACL. In Type 3 , there is midsubstance tear between $25 \%$ and $75 \%$ of the ACL. Types 4 and 5 are the distal tears, with $10 \%-25 \%$ of the distal $\mathrm{ACL}$ remaining intact in Type 4, and less than $10 \%$ of the distal ACL left intact. Type 5 tears can be divided into two groups, as soft tissue avulsions (type $\vee A$ ) or bony avulsions of tibial insertion (type $\vee B$ ). In the decision of arthroscopic primary ACL repair, this classification is very helpful.

In addition, the tissue quality can be classified as good, fair, and poor. If all fibers are intact in the same direction with a homo- 
geneous signal, it is called a good quality tissue. If some fibers are in the same direction with a mildly heterogeneous signal, it is called a fair quality tissue, and if most fibers are in different directions with heterogeneous signal, it is called a poor quality tissue. Tears with good tissue quality must be preferred for an arthroscopic $A C L$ repair.

\section{CONCLUSION}

Patients with a suspected ACL tear are diagnosed with an MRI scan. It is accepted that MRI is the most effective radiological modality, with $90 \%-95 \%$ sensitivity and $95 \%-100 \%$ specificity for detecting ACL injuries. Historically, MRI is mainly used to determine the $A C L$ injury and to discern whether the tear is partial or complete. However, recently the MRI targeting has been expanded. Nowadays, the MRI classification of the remnant tissue quality and the localization of the ACL tear are the most important findings for primary arthroscopic $A C L$ repair. As a result, choosing the right surgical technique for the $\mathrm{ACL}$ tear treatment is easier with these findings and the MRI help.

Peer-review: Externally peer-reviewed.

Author Contributions: Concept - B.P., M.A.D., A.E.P.; Design - B.P., M.A.D.; Supervision - B.P., M.A.D.; Resource - B.P., M.A.D., A.E.P.; Materials - B.P., M.A.D.; Data Collection and/or Processing - B.P., M.A.D., A.E.P.; Analysis and/or Interpretation - B.P., M.A.D., A.E.P.; Literature Search - B.P., M.A.D., A.E.P.; Writing - B.P., M.A.D., A.E.P.; Critical Reviews - B.P., M.A.D., A.E.P.

Conflict of Interest: The authors have no conflicts of interest to declare.

Financial Disclosure: The authors declared that this study has received no financial support.

\section{REFERENCES}

I. Gianotti SM, Marshall SW, Hume PA, Bunt L. Incidence of anterior cruciate ligament injury and other knee ligament injuries: a national population-based study. J Sci Med Sport 2009; 12: 622-7. [CrossRef]

2. Von Porat A, Roos EM, Roos H. High prevalance of osteoarthritis 14 years after an anterior cruciate ligament tear in male soccer players: a study of radiographic and patient relevant outcomes. Ann Rheum Dis 2004; 63: 269-73. [CrossRef]

3. Feagin JA, Abbott HG, Rokous JR. The isolated tear of the anterior cruciate ligament. J Bone Joint Surg Am 1972; 54: 1340-I.

4. Marshall JL, Warren RF, Wickiewicz TL. Primary surgical treatment of anterior cruciate ligament lesions. Am J Sports Med 1982; 10: 1037. [CrossRef]

5. Gobbi A, Mahajan $\vee$, Karnatzikos G, Nakamura N. Single versus double bundle $A C L$ reconstruction: Is there any difference in stability and function at 3-year follow up? Clin Orthop Relat Res 2012; 470: 824-34. [CrossRef]

6. Jansson KA, Linko E, Sandelin J, Harilainen A. A Prospective randomized study patellar versus hamstring tendon autografts for anterior cruciate ligament reconstruction. Am J Sports Med 2003; 31: 12-8. [CrossRef]

7. Girgis FG, Marshall JL, Monajem A. The cruciate ligaments of the knee joint. Anotomical, functionl and experimental analysis. Clin Orthop Rel Res 1975; 106: 216-31. [CrossRef]

8. Chouteau J, Testa R, Viste A, Moyen B. Knee rotational laxity and proprioceptive function 2 years after partial $\mathrm{ACL}$ reconstruction. Knee Surg Sports Traumatol Arthrosc 2012; 20: 762-6. [CrossRef]

9. Sonnery-Cottet B, Panisset JC, Colombet P, Cucurulo T, Graveleau $N$, Hulet $C$, et al. Partial $A C L$ reconstruction with preservation of the posterolateral bundle. Orthop Trumatol Surg Res 2012; 98(Suppl 8): SI65-70. [CrossRef]
10. Difelice GS, Villegas C, Taylor S. Anterior cruciate ligament preservation: early results of a novel arthroscopic tecnique for suture anchor primary anterior cruciate repair. Arthroscopy 2015; 31: 216271. [CrossRef]

II. Achtnich A, Herbst E, Forkel P, Metzlaff S, Sprenker F, Imhoff AB, et al. Acute proximal anterior cruciate ligament tears: outcomes after arthroscopic suture anchor repair versus anatomic single-bundle reconstruction. Arthroscopy 2016; 32: 2562-9. [CrossRef]

12. Smith JO, Yasen SK, Palmer HC, Lord BR, Britton EM, Wilson AJ. Paediatric $A C L$ repair reinforced with temporary internal bracing. Knee Surg Sports Traumatol Arthrosc 2016; 24: 1845-5I. [CrossRef]

13. Klass D, Toms AP, Greenwood R, Hopgood P. MR imaging of acute anterior cruciate ligament injuries. Knee 2007; 14: 339-47. [CrossRef]

14. Ha TP, Li KC, Beaulieu CF, Bergman G, Ch'en IY, Eller DJ, et al. Anterior cruciate ligament injury: fast spin-echo MR imaging with arthroscopic correlation in 217 examinations. AJR Am J Roentgenol 1998; 170: 1215-9. [CrossRef]

15. Robertson PL, Schweitzer ME, Bartolozzi AR, Ugoni A. Anterior cruciate ligament tears: evaluation of multiple signs with MR imaging. Radiology 1994; 193: 829-34. [CrossRef]

16. Bomberg BC, McGinty JB. Acute hemarthrosis of the knee: indications for diagnostic arthroscopy. Arthroscopy 1990; 6: 221-5. [CrossRef]

17. Dunn WR, Spindler KP, Amendola A, Andrish JT, Kaeding CC, Marx $R G$, et al. Which preoperative factors, including bone bruise, are associated with knee pain/symptoms at index anterior cruciate ligament reconstruction (ACLR)? A Multicenter Orthopaedic Outcomes Network (MOON) ACLR Cohort Study. Am J Sports Med 2010; 38: 1778-87. [CrossRef]

18. Cobby MJ, Schweitzer ME, Resnick D. The deep lateral femoral notch: an indirect sign of a torn anterior cruciate ligament. Radiology 1992; 184: 855-8. [CrossRef]

19. Collins MS, Unruh KP, Bond JR, Mandrekar JN. Magnetic resonance imaging of surgically confirmed anterior cruciate ligament graft disruption. Skeletal Radiol 2008; 37: 233-43. [CrossRef]

20. Claes S, Luyckx T, Vereecke E, Bellemans J. The Segond fracture: a bony injury of the anterolateral ligament of the knee. Arthroscopy 2014; 30: 1475-82. [CrossRef]

21. Claes S, Vereecke E, Maes M, Victor J, Verdonk P, Bellemans J. Anatomy of the anterolateral ligament of the knee. J Anat 2013; 223: 321-8. [CrossRef]

22. Vincent JP, Magnussen RA, Gezmez F, Uguen A, Jacobi M, Weppe $F$, et al. The anterolateral ligament of the human knee: an anatomic and histologic study. Knee Surg Sports Traumatol Arthrosc 2012; 20: 147-52. [CrossRef]

23. Kızılgöz V, Sivrioğlu AK, Aydın H, Çetin T, Ulusoy GR. Assessment of the anterolateral lgament of the knee by $1.5 \mathrm{~T}$ magnetic resonance imaging. J Int Med Res 2018; 46: 1486-95. [CrossRef]

24. Helito $\mathrm{CP}$, Helito PVP, Costa HP, Demange MK, Bordalo-Rodrigues M. Assessment of the Anterolateral Ligament of the Knee by Magnetic Resonance Imaging in acute injuries of the anterior cruciate ligament. Arthroscopy 2017; 33: 140-6. [CrossRef]

25. Vahey TN, Hunt JE, Shelbourne KD. Anterior translocation of the tibia at MR imaging: a secondary sign of anterior cruciate ligament tear. Radiology 1993; 187: 817-9. [CrossRef]

26. Gentili A, Seeger LL, Yao L, Do HM. Anterior cruciate ligament tear: indirect signs at MR imaging. Radiology 1994; 193: 835-840. [CrossRef]

27. Boeree NR, Ackroyd CE. Magnetic resonance imaging of anterior cruciate ligament rupture. J Bone Joint Surg (Br) 1992; 74-B: 614-6. [CrossRef]

28. Ahn JM, Kang HS, Kim SM, Seong SC. Injury of the ligaments of the knee: magnetic resonance evaluation. J Korean Radiol Soc 1992; 28: 269-74. [CrossRef]

29. Yoo JD, Lim HM. Morphologic changes of the posterior cruciate ligament on magnetic resonance imaging before and after reconstruction of chronic anterior cruciate ligament ruptures. Knee Surg Relat Res 2012; 24: 241-4. [CrossRef] 
30. Paper AR. Partial tears of the anterior cruciate ligament: diagnosis and treatment. Am J Orthop 20II; 40: 2-7.

31. Christel PS, Akgun U, Yasar T, Karahan M, Demirel B. The contribution of each anterior cruciate ligament bundle to the lachmann test: a cadaver investigation. J Bone Joint Surg Br 2012; 94: 68-74. [CrossRef]

32. Naraghi A, White LM. MR imaging of cruciate ligaments. Magn Reson Imaging Clin N Am 2016; 22: 557-80. [CrossRef]

33. Gokalp G, Demirag B, Nas OF, Aydemir MF, Yazici Z. Contribution of thin slice ( $\mathrm{mm}$ ) oblique coronal proton density-weighted MR images for assessment of anteromedial and posterolateral bundle damage in anterior cruciate ligament injuries. Eur J Radiol 2012; 81: 2358-65. [CrossRef]

34. Delin C, Silvera S, Coste J, Thelen P, Lefevre N, Ehkirch FP, et al. Reliability and diagnostic accuracy of qualitative evaluation of diffusion-weighted MRI combined with conventional MRI in differentiating between complete and partial anterior cruciate ligament tears. Eur Radiol 2013; 23: 845-54. [CrossRef]

35. Allen $C R$, Giffin $C R$, Harner CD. Revision anterior cruciate ligament reconstruction. Orthop Clin North Am 2003; 34: 79-98. [CrossRef]

36. Imhauser C, Mauro C, Choi D, Rosenberg E, Mathew S, Nguyen J, et al. Abnormal tibiofemoral contact stress and its association with altered kinematics after center-center anterior cruciate ligament reconstruction: an in vitro study. Am J Sports Med 20I3; 4I: 8I5-25. [CrossRef]

37. Song EK, Seon JK, Yim JH, Woo SH, Seo HY, Lee KB. Progression of osteoarthritis after double- and single-bundle anterior cruciate ligament reconstruction. Am J Sports Med 2013; 4I: 2340-6. [CrossRef]

38. Murray MM, Fleming BC. Use of a bioactive scaffold to stimulate anterior cruciate ligament healing also minimizes posttraumatic osteoarthritis after surgery. Am J Sports Med 2013; 4I: 1762-70. [CrossRef]

39. Van der List JP, DiFelice GS. Range of motion and complications following primary repair versus reconstruction of the anterior cruciate ligament. Knee 2017; 24: 798-807. [CrossRef]

40. Sherman MF, Lieber L, Bonamo JR, Podesta L, Reiter I. The longterm followup of primary anterior cruciate ligament repair. Defining a rationale for augmentation. Am J Sports Med 1991; 19: 243-55. [CrossRef]

4l. Van der List JP, DiFelice GS. Preoperative magnetic resonance imaging predicts eligibility for arthroscopic primary anterior cruciate ligament repair. Knee Surg Sport Traumatol Arthrosc 2018; 26: 66071. [CrossRef] 